\title{
Qualidade da educação: cinco lembretes e uma lembrança
}

NÍLSON JOSÉ MACHADO

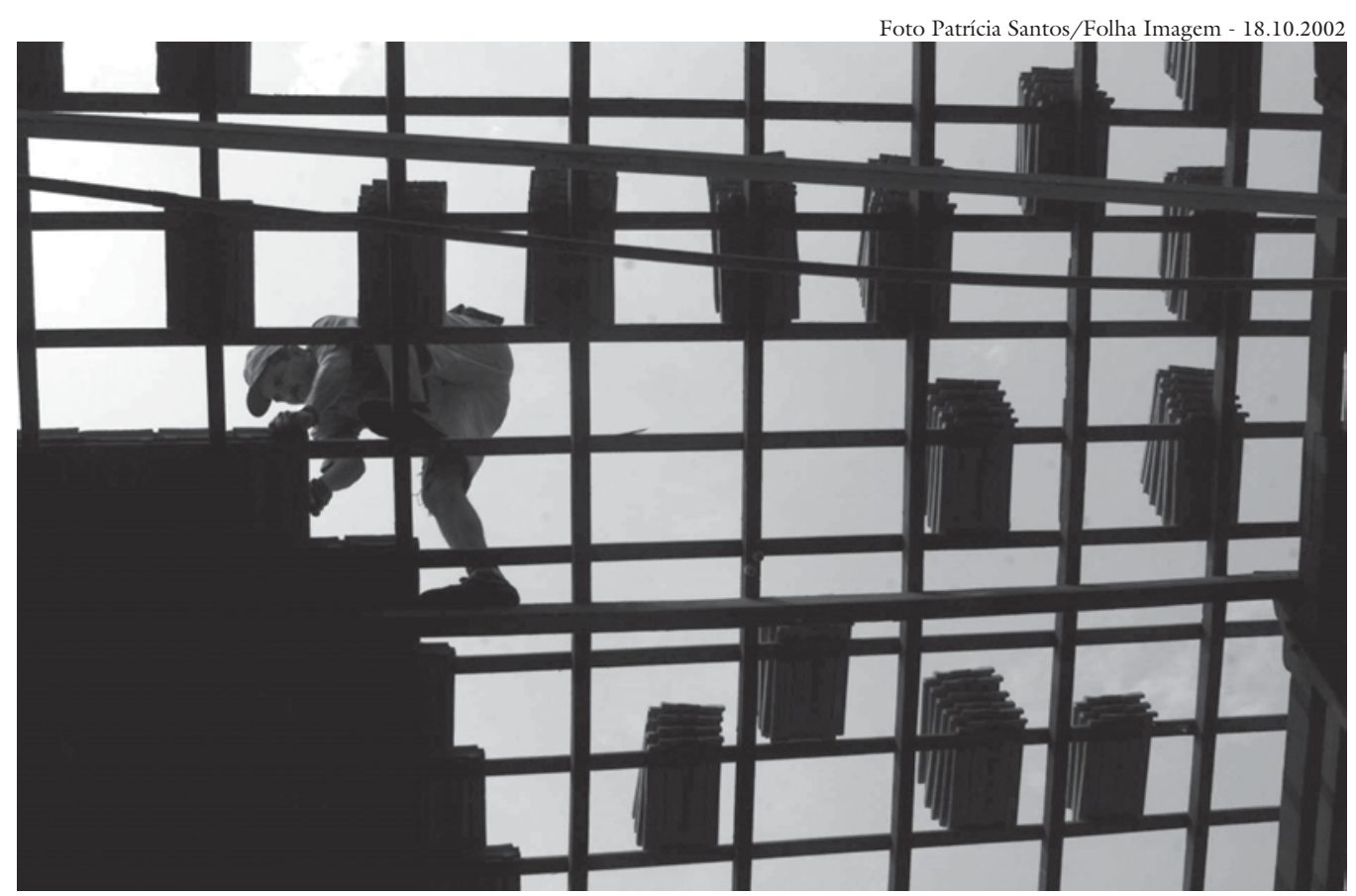

Antigo barracão da Fepasa passa por reforma para abrigar a Fatec de Jundiai (SP).

\section{Introdução: a qualidade da educação}

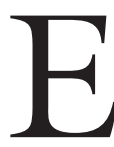

XISTE um aparente consenso com relação ao fato de que a educação brasileira é de má qualidade. Os mais variados indicadores, em diferentes processos de avaliação, em âmbitos regionais, nacionais ou internacionais, parecem tornar tal fato indiscutível. Na verdade, a situação é tão crítica que, mesmo sem os inúmeros termômetros disponíveis, salta aos olhos o fato de que o paciente está febril. Os diagnósticos costumam ser renitentes: as condições materiais da maior parte das escolas são precárias, a formação e a dedicação de muitos professores deixam a desejar, os currículos são inadequados, os recursos disponibilizados não são suficientes, os alunos não parecem interessados, as condições familiares e socioeconômicas não contribuem para uma participação efetiva dos pais na vida escolar dos estudantes etc.

Não faltam planos de ações governamentais visando ao enfrentamento dos problemas. Já tivemos o Plano Decenal de Educação para Todos (1993-2003), agora temos o Programa de Desenvolvimento da Educação, com ações que se 
prolongam de 2007 até 2022. Os novos planos e programas são recebidos, em geral, com euforia. Como fogos de artifício, no entanto, eles produzem efeitos visuais interessantes - enchem as páginas dos jornais e revistas de manchetes esperançosas -, mas seus efeitos têm sido muito modestos, e suas promessas costumam ser, paulatinamente, esquecidas.

Sem dúvida, algo vai mal com a educação brasileira. Tarefas urgentes, que muitos países de nosso continente praticamente realizaram no século XIX, como a eliminação do analfabetismo, parecem, para nós, eternos desafios. Sintomaticamente, a Lei Magna do país registra a necessidade da existência de um Plano Nacional de Educação, renovado a cada cinco anos, que tem como uma das metas a eliminação do analfabetismo, como se tal tarefa fosse perene. E com muito desconforto verificamos que o número de analfabetos no país era superior a 15 milhões em 1960 e permanece acima desse patamar ainda hoje. A oferta de ensino fundamental para todas as crianças na idade adequada tornou-se praticamente efetiva, nos últimos dez anos, mas certamente é enganadora, uma vez que a qualidade do ensino não logrou atingir um nível aceitável. Do modo como se realiza, tende a perpetuar uma alfabetização fictícia, de efeitos paliativos e ilusórios, como o de desenhar o próprio nome sem a mínima compreensão do que se expressa, ou anunciar resultados de cálculos matemáticos sem nenhuma consciência do que significam.

Não se trata apenas de uma carência de investimentos, como muitas análises costumam inferir. O Chile e a Argentina investem uma porcentagem do PIB bem menor que a nossa, e, a despeito de seus problemas educacionais, aparecem melhor que nós em qualquer fotografia originada nos indicadores que nos denigrem. Para citar apenas um exemplo: nenhum país do mundo investe tanto na distribuição de livros didáticos para a educação básica quanto o Brasil. Pelo menos 60 milhões de livros por ano desde 1993; mais de 120 milhões nos últimos anos. A despeito da grande alegria das editoras, os resultados efetivos de tal aporte de recursos não são facilmente perceptíveis. A centralização na distribuição faz que, em alguns casos, os livros nem cheguem ao destinatário final, ou o façam em épocas inoportunas, tendo em vista o desenrolar do ano letivo. A voz do professor deveria ser muito mais importante do que o é no momento da escolha. Seria um contra-senso afirmar-se que os livros doados atrapalham, mas a situação serve de exemplo para ilustrar o fato de que o modo como os investimentos são administrados e distribuídos é mais importante do que seu montante.

No que se segue, pretendemos pôr entre parênteses os elementos da suposta evidência da má qualidade da educação brasileira e examinar o fenômeno sem utilizar os óculos consensuais anteriormente referidos. O objetivo da análise é destacar cinco aspectos da questão, cinco lembretes sem cuja consideração não parece possível vislumbrar alternativas de ações concretas, institucionalizáveis, que nos permitam escapar do eterno recomeçar que costuma pautar as políticas educacionais, e a que parecem condenados, como Sísifo, os profissionais da educação. De forma resumida, os cinco lembretes são os seguintes: 
- ainda que os resultados gerais da Educação Básica sejam sofríveis, existe, no Brasil, educação de qualidade, não sendo aceitável a pressuposição subjacente às políticas públicas de que as ações educacionais realizam-se sobre uma "terra arrasada";

- os instrumentos de avaliação são necessários, mas eles devem ser meios para instrumentar a ação e não apenas motes para a produção de manchetes espetaculares;

- nenhuma política educacional pode produzir resultados positivos sem uma integração orgânica entre os diversos níveis de ensino, particularmente entre a Educação Básica e o Ensino Superior;

- a escola, e não os professores ou os alunos, deve constituir a unidade fundamental na relação entre as diversas instâncias do poder público e a rede de ensino;

- é imprescindível que as condições de trabalho dos professores da Educação Básica melhorem substancialmente, uma vez que eles são os elementos decisivos para a fecundação de qualquer política educacional.

\section{Má qualidade: uma generalização indevida}

Comecemos com uma proposição acaciana: no Brasil existem escolas em que se realiza uma educação de muita qualidade, tanto no ensino público quanto no ensino privado. A cada nova divulgação de resultados de algum processo de avaliação, simultaneamente com a ocorrência de manchetes catastróficas, surgem exceções que parecem apenas confirmar a regra, mas que, na verdade, servem para ilustrar a afirmação feita: existe, entre nós, educação de qualidade. É certo que o número de boas escolas é muito pequeno, em relação ao tamanho da rede de ensino - das cerca de cinco mil escolas de São Paulo, poderíamos mencionar, digamos, duzentas ou trezentas que se destacam, ao longo dos cerca de seiscentos municípios do Estado. Viajando pelo Brasil, em todos os Estados é possível identificar escolas que se destacam pelo seu desempenho nos exames, ou que, reconhecidamente, realizam uma educação de qualidade. Ignorar a existência de tais escolas diferenciadas tratando a totalidade da rede como se fosse constituída apenas por escolas problemáticas é um incrível erro de estratégia que se vai repetindo, a cada novo programa de reforma educacional.

De fato, as iniciativas transformadoras partem do princípio de que tudo deve começar do zero: todos os professores precisam ser capacitados, todas as escolas precisam construir seu projeto institucional etc. $\mathrm{Na}$ verdade, as boas escolas já dispõem de professores capacitados, em sua maioria, havendo a necessidade tópica de uma capacitação eventual, além da necessidade natural de uma formação continuada. Também é verdade que não existem exemplos de escolas bem-sucedidas que prescindam de um projeto consistente, que resulta, em grande parte, de seu enraizamento em uma comunidade, ou em determinada cultura institucional. Às vezes, tal projeto existe tacitamente, não se encontrando um registro explícito desse em parte alguma; insistimos, no entanto, no fato 
de que uma boa escola não pode prescindir de um projeto institucional. Ao nivelar todas as escolas por baixo, os programas governamentais podem garantir a atenção às que realmente necessitam de tudo, mas certamente desestimulam - e até certo ponto desrespeitam - aquelas que já funcionam de modo satisfatório, necessitando apenas de apoio e aprimoramento.

Uma maneira de evitar tal desvio seria a consolidação de uma política de procurar aumentar o número das escolas que já funcionam bem, que já apresentam uma qualidade satisfatória. Para tanto, seria fundamental, inicialmente, identificar de modo criterioso tais escolas, uma vez que elas somente aparecem nos momentos em que as manchetes espalhafatosas apresentam a educação nacional como uma grande hecatombe. Elas são apresentadas como pontos fora da curva, como elementos excepcionais em um conjunto de contra-exemplos. Curiosamente, não se procura dar a voz a tais escolas, buscando compreender as razões de seu desempenho, para fazer que outras pudessem aprender com elas. As matérias jornalísticas que exploram o modo de funcionamento das escolas diferenciadas chamam a atenção para certas características interessantes delas, mas tais fatores não são considerados de modo sistemático, objetivando-se uma inspiração ou um contágio de toda a rede. Se uma escola que apresenta o melhor desempenho numa avaliação nacional valoriza especialmente o trabalho do professor, ensina latim e xadrez, ocupa os alunos seis ou sete horas por dia, os provê de atividades significativas que aproximam a educação e a cultura, isso não pode ser encarado apenas como um conjunto de características fortuitas. Ao pretenderem propor caminhos novos que ignoram as vias já percorridas pelas boas escolas existentes, os órgãos públicos tentam reinventar a roda e, muitas vezes, mesmo inintencionalmente, castram ou desestimulam iniciativas que deveriam ser louvadas e consideradas inspiradoras.

Escolas boas sempre existiram, sempre existirão, assim como também sempre existirão escolas mais simples, com desempenho mais fraco. O ideal a ser buscado é o de que todas as escolas possam ter as condições necessárias para um funcionamento satisfatório, do ponto de vista de sua atividade-fim, que é a formação pessoal de seus alunos. E que um número cada vez maior delas atinja realmente um nível ótimo de desempenho. A perspectiva de que todas as escolas tenham desempenhos iguais, ou tenham o mesmo nível de resultados, espelhadas em determinado padrão, fixado externamente, é utópica, não tem fundamento na realidade concreta. As escolas sempre serão diferentes, como as pessoas são diferentes, em decorrência da diversidade de seus projetos. A busca da qualidade na educação nem de longe pode ser assemelhada a uma caracterização dicotômica das escolas, em que uma coleção de zeros deve aspirar a tornarse uma coleção de uns.

\section{Instrumentos de avaliação: os meios e os fins}

A educação brasileira vai mal; muitos afirmam que "os dados falam por si". Trata-se, no entanto, de uma afirmação falaciosa: os dados apenas respondem a 
perguntas que nós previamente a eles formulamos. Se nos debruçarmos sobre eles sem questões explícitas, nenhuma proposição deles extrairemos. Os exames do Sistema de Avaliação da Educação Básica (Saeb), realizados pelo Instituto Nacional de Estudos e Pesquisas Educacionais (Inep) desde 1990, deveriam servir de base para orientar as políticas públicas na área da educação. Os bancos de dados atinentes aos exames são imensos: tudo se encontra minuciosamente registrado em diferentes meios - impressos, eletrônicos etc. Carecem, no entanto, de significados, de interpretações norteadoras que somente poderiam resultar de perguntas prévias aos registros. A aparência é a de que tudo se registrou, sem uma razão clara para isso, na vã expectativa de que "os dados falassem por si”.

Admitindo-se que as perguntas existem e são nítidas, ao recorrermos aos dados para obtermos as respostas, corremos novos riscos. Os números podem esconder ou revelar, dependendo de como são utilizados. Diz-se freqüentemente que os números não mentem; é preciso lembrar, no entanto, que mentirosos costumam recorrer a números para alinhavar seus argumentos. As análises dos resultados de processos de avaliação costumam realizar torções semânticas incríveis para ajustar uma interpretação racional aos dados existentes. Por exemplo, nos resultados do Exame Nacional do Ensino Médio (Enem) correspondentes ao ano de 2006, as notas mais baixas dos alunos em relação ao ano anterior foram interpretadas de diversos modos, sempre partindo do pressuposto de que as provas dos dois anos teriam sido realizadas com o mesmo nível de dificuldade, ou que, pelo menos, o essencial da metodologia do referido exame tivesse sido preservado. Em vez do contorcionismo para tentar explicar o desempenho mais fraco dos alunos, talvez tivesse sido mais apropriado avaliar a propriedade do instrumento de avaliação utilizado. De fato, as características originais do exame do Enem, essencialmente distinto de um exame do tipo vestibular, foram se matizando a tal ponto que, na realização do exame correspondente ao ano de 2006, havia pouca diferença entre a prova apresentada aos estudantes e um típico exame vestibular. A proposta básica de elaboração de apresentação de três questões para cada habilidade da matriz de competências e habilidades do Enem foi até certo ponto esquecida, e as questões apresentadas chegaram mesmo a ser separadas por disciplinas, o que distancia significativamente o exame das intenções originais. Não é o caso aqui de avaliar-se a qualidade do instrumento, mas sim de afirmar-se enfaticamente que os resultados dos dois exames não podem ser comparados como o foram, não sendo legítima a conclusão de que os alunos tiveram um desempenho mais fraco.

Quando se recorre a instrumentos internacionais como o Program for International Student Assessment (Pisa), por exemplo, outros são os ruídos na realização ou na comunicação dos resultados. Nem sempre o modo como as questões são formuladas ou as condições em que as provas são realizadas leva em consideração certas peculiaridades das diferentes culturas, o que vicia grande parte das comparações resultantes. É certo que existem certas competências mínimas que seriam relativamente independentes de tal diversidade, e que de- 
veriam ser passíveis de avaliação em todos os contextos culturais, mas isso não elide o fato de que uma avaliação que não leva em consideração a diversidade de projetos educacionais dos países em que é realizada não pode ter seus resultados interpretados de modo tão conclusivo como sói acontecer.

De modo geral, os resultados de um processo de avaliação são analisados como se tivessem o significado e a precisão de uma medida em sentido físico ou matemático. Os instrumentos utilizados, no entanto, situam-se bem longe de tal pensamento desejoso. Em sentido próprio, as medidas resultam da comparação entre uma grandeza e um padrão: no caso da avaliação, não existe nitidez nem na "grandeza" a ser medida nem no padrão a ser adotado. No fundo, avaliamos pessoas, e os supostos padrões somente poderiam decorrer da existência de um projeto educacional com um mínimo de nitidez, o que inexiste, no caso brasileiro. E os números que resultam de toda pseudomedida avaliativa são como indícios de algo que não dispensa uma interpretação mais complexa do que a simples leitura do mostrador de um instrumento de medida

Um enorme complicador no caso brasileiro é o fato de que coexistem sem dialogar diversos instrumentos de avaliação, operando nos diferentes sistemas de ensino: Sistema Nacional de Avaliação da Educação Básica (Saeb), Sistema de Avaliação de Rendimento Escolar do Estado de São Paulo (Saresp), Enem, Prova Brasil etc. Nem mesmo a idéia de competência no âmbito das disciplinas, que orienta a formulação do exame do Saeb, está em sintonia com a matriz de competências do Enem, de natureza transdisciplinar. Cada um desses exames produz números desagradáveis, mas a falta de uma integração orgânica entre eles faz que não colaborem na construção de uma interpretação consistente dos problemas, na prefiguração de ações que possam efetivamente transformar a situação. Mas as dificuldades não param por aí: cada nova iniciativa para enfrentar os problemas educacionais costuma mencionar a criação de novos instrumentos de avaliação, como se os problemas decorressem da ausência deles. A Provinha Brasil, anunciada recentemente, e que deve ser aplicada a crianças entre seis e oito anos, é apenas mais um exemplo de tal expectativa de corrigir as causas atacando os efeitos. Sem dúvida, se os instrumentos são criados para produzir resultados gritantes, eles cumprem efetivamente sua função; resta apenas o fato de que eles praticamente se limitam aos gritos, não instrumentando a ação. São eficazes na produção de manchetes, na geração de atritos, mas não produzem nenhum resquício de luz.

Para concluir, retornemos ao ponto de partida destas rápidas considerações sobre os instrumentos de avaliação. Registramos, no início, que os exames do Saeb deveriam servir de base para orientar políticas públicas na área de Educação. De modo geral, qualquer processo de avaliação sempre deveria ter as características de um meio para instrumentar as ações educacionais, para qualificar as intervenções dos responsáveis por elas. As avaliações não podem constituir um fim em si mesmo. Não parece fazer nenhum sentido um governante incluir em seus projetos - e vangloriar-se disso - a criação de tal ou qual instrumento de 
avaliação, como se pretendesse enfrentar a febre com um novo termômetro. Tão certo quanto o fato de que tais instrumentos são necessários é a clareza de que, entre nós, os problemas educacionais não decorrem da inexistência deles. E a inexistência de vínculos efetivos entre os diagnósticos decorrentes dos processos avaliativos e as ações idealizadas para o suposto enfrentamento dos problemas contribui decisivamente tanto para a ineficácia das ações quanto para o desprestígio dos instrumentos de avaliação.

\section{Um dilema indevido: Educação Básica versus Ensino Superior}

$\mathrm{Na}$ análise das razões da crise educacional brasileira, não é raro afirmar-se que, na raiz dos problemas, estaria o fato de o Brasil gastar mais com o Ensino Superior do que com a Educação Básica. Ilustra-se tal asserção a partir de números representativos dos investimentos do governo federal em tais níveis de ensino, e o maior gasto com o Ensino Superior parece efetivamente comprovado. Trata-se, no entanto, de uma afirmação desprovida de significado, em razão de um pecado original: ao governo federal compete efetivamente promover o Ensino Superior, atuando apenas de modo circunstancial nos outros níveis. De modo geral, a Educação Básica é da competência dos Estados e dos municípios, sendo o Ensino Fundamental da competência prioritária dos municípios e supletiva dos Estados. Quando se leva tal fato em consideração, observa-se que os gastos governamentais com a educação, considerados os diversos níveis de governo, são, aproximadamente, seis a sete vezes maiores com a Educação Básica do que com o Ensino Superior, o que parece natural e não caracteriza nenhuma distorção crônica.

Curiosamente, quase quinze anos após o falecido Plano Decenal de Educação para Todos, um membro permanente do Conselho Nacional de Educação, que também é diretor executivo do Movimento Compromisso de Todos pela Educação, criado por um grupo de empresários envolvidos com o chamado Terceiro Setor, defende, atualmente, um aumento relativo nos gastos com o Ensino Superior. Em entrevista a um grande jornal de São Paulo (OESP, 29.4.2007), afirma em alto bom som: o ideal para o Brasil seria aplicar em educação não os atuais 3,2\% para a Educação Básica e 0,5\% para o Ensino Superior, mas sim 6,0\% do PIB, sendo 5,0\% para a Educação Básica e 1,0\% para o Ensino Superior!

Alguns analistas, renitentes no argumento do suposto privilegiamento do Ensino Superior, costumam quantificar o gasto por aluno, exibindo um montante efetivamente maior na universidade do que na Educação Básica. O que é, sem dúvida, verdadeiro, e também parece absolutamente natural, em decorrência dos diferentes contextos e circunstâncias. A associação direta entre o ensino e a pesquisa, por exemplo, constitui um indício eloqüente da naturalidade do maior custo per capita no ensino universitário.

Parece claro, no entanto, que, entre nós, uma discussão sobre gastos relativos nos diversos níveis de ensino é absolutamente inócua, no que se refere a um enfrentamento efetivo dos problemas educacionais. É possível que falte pão em todos os níveis de ensino - ou não. Mas é certo que existe uma profunda 
desarticulação entre os diversos níveis, o que possibilita diferentes anomalias e mazelas. Uma delas é o fato de que os alunos da Educação Básica pública destinam-se, em sua ampla maioria, ao Ensino Superior privado (pago), ao mesmo tempo que os alunos do Ensino Médio privado (pago) ocupam a maior parte das vagas do Ensino Superior público. Tal descontinuidade, persistente e gritante, consolida e amplifica uma injusta distribuição de recursos, em um cenário em que pontificam as extremas desigualdades de renda e o desequilíbrio na distribuição de tributos entre assalariados e empresas.

Um outro ponto em que a desarticulação supra-referida é evidente é o fato de que o país ostenta um sistema de Pós-Graduação e Pesquisa com algum destaque internacional, ao mesmo tempo que o Ensino Fundamental apresenta um desempenho abaixo de qualquer expectativa minimamente razoável. Não parece compreensível tal convivência abstrusa: formamos milhares de doutores por ano e continuamos a contabilizar milhões de analfabetos stricto sensu, e dezenas de milhões de analfabetos funcionais. Somente na trilha de uma verdadeira esquizofrenia entre os níveis Básico e Superior de ensino, resultante de uma ausência quase total de compromisso, de integração, de partilha de responsabilidades entre os envolvidos, podem surgir contestações contábeis como as daqueles que consideram excessivos os gastos com a universidade.

A gravidade e a profundidade da crise em que se encontra a educação pública brasileira não parecem solucionáveis por meio de medidas contábeis, com meros deslocamentos de recursos de um dos setores para outro. Somente um tratamento de choque poderia viabilizar uma articulação efetiva entre os diversos níveis de ensino, fazendo que todos os profissionais competentes existentes nas universidades se mobilizassem em busca de um ponto de inflexão na melhoria da Educação Básica. Como uma experiência de pensamento, permitamo-nos um delírio: sonhemos com um pacto nacional que viabilizasse uma integração efetiva entre os diversos níveis de ensino. Tal como se estabelece nas disposições transitórias, quando se muda uma Lei Magna, como a Constituição, seria o caso de se projetar legalmente um mutirão que vigorasse durante um curto período - três a cinco anos, talvez - em que todos os professores da universidade pública, como uma força-tarefa, irmanados com os da escola básica, colocassem suas competências a serviço da formação dos alunos do Ensinos Fundamental e Médio, deixando de lado provisoriamente suas mais caras pesquisas, seus mais alentados projetos pessoais. Nada parece mais importante, do ponto de vista educacional, do que a produção de tal inflexão. Talvez apenas os pesquisadores da área da Saúde tivessem razões justas para serem poupados de tal conjuminação de esforços. Somente uma medida de tal ordem, que simbolizasse um envolvimento, uma participação, uma assunção tão nítida de responsabilidades, poderia transformar significativamente a situação crítica vigente.

$\mathrm{Na}$ verdade, o sistema de ensino público precisa ser pensado como um corpo único, com seus diversos órgãos em perfeito funcionamento; a doença poderá minar a saúde se atacar qualquer um deles, seja a cabeça, seja o cora- 
ção, sejam os pulmões... Se as responsabilidades com a educação pública forem devidamente assumidas, a autoridade da universidade como usina de idéias e valores norteadores da nação estará naturalmente preservada e não serão mais pertinentes associações entre a crise educacional e os supostos gastos excessivos com o Ensino Superior.

\section{Uma questão crucial: a escola como unidade}

No enfrentamento dos problemas educacionais, em busca da melhoria da qualidade, são raras as situações em que a escola tem sido considerada a unidade fundamental na relação entre as diversas instâncias do poder público e a rede de ensino. Com muito mais freqüência, na quase totalidade dos casos, os alunos ou os professores é que são assim considerados.

Oferecem-se cursos de capacitação, por exemplo, diretamente aos professores. Mesmo sendo apreciados pela maior parte deles, tais cursos conduzem a resultados pouco expressivos, no que se refere à produção de resultados melhores nos exames. Ao que tudo indica, por atenderem individualmente os professores, sem a mediação das necessidades e dos projetos das unidades escolares, tais cursos de capacitação não conseguem modificar a prática efetiva dos professores beneficiários. De modo otimista, poder-se-ia dizer que eles se sentem andorinhas isoladas, em seus locais de trabalho. De modo análogo, distribuem-se livros didáticos aos alunos de modo relativamente perdulário, que atende primordialmente aos interesses das editoras: a cada novo ano, nova e farta distribuição. Ainda que assumam um compromisso formal de devolvê-los após a utilização, estatísticas oficiais revelam que quase metade dos alunos não o faz.

Em ambos os casos citados, a unidade escolar é que deveria estar no centro das atenções. Na capacitação docente, a busca do atendimento das demandas das escolas, ou dos professores de cada unidade escolar, possibilitaria um enraizamento dos aperfeiçoamentos realizados. Os professores não podem encarar sua tarefa específica como um empreendimento solitário. A perspectiva de uma capacitação inteiramente externa, que ignore as potencialidades da própria equipe escolar, é desmobilizadora. A colaboração e a solidariedade dos colegas na busca da realização do projeto coletivo da unidade escolar são elementos fundamentais. Em vez de cursos tópicos, seria muito mais fecunda a abertura de canais permanentes de interação entre as instituições formadoras e as escolas como unidade de ensino, possibilitando consultas regulares e apoios permanentes, quando solicitados pelas escolas.

No caso da distribuição de livros, a unidade escolar deveria ser, sempre, a beneficiária da doação. A julgar pelas quantidades disponibilizadas anualmente, em dois ou três anos, todos os alunos da rede pública teriam todos os livros, de todas as matérias, disponíveis em suas salas de aula, para uso durante os trabalhos em classe. Após tal suprimento, mantidos os níveis de distribuição atuais, em mais dois ou três anos, as bibliotecas escolares teriam recebido um acervo respeitável, suficiente para que todos os alunos que o desejassem pudessem re- 
tirar livros e levar consigo para estudar em casa. Depois desses poucos anos, a distribuição de livros poderia significar uma renovação eventual, a cada período de seis ou oito anos, e um enriquecimento do acervo das bibliotecas, com o acréscimo de obras não-didáticas. Do ponto de vista da escola, tal perspectiva pressupõe uma estabilidade mínima na utilização dos livros didáticos, cuja adoção não significaria uma submissão do professor às idéias e aos encaminhamentos pedagógicos de um único autor. Do ponto de vista das editoras, o pressuposto é que elas passassem a se contentar, paulatinamente, em vender para o governo muito mais títulos - e muito menos livros por título - contrariamente ao sonho atual, de vender milhões de exemplares de uns poucos títulos.

Ter a escola como unidade significaria, ainda e principalmente, apoiar as unidades escolares para que a direção de cada uma delas pudesse exercer a liderança necessária na condução dos projetos coletivos prefigurados e solidariamente desenvolvidos. O papel do diretor de uma escola é freqüentemente subestimado, não existindo condições objetivas para que os diretores assumam as responsabilidades inerentes ao exercício de sua legítima autoridade, de sua necessária liderança. Naturalmente, tal liderança não pode prescindir da participação efetiva dos professores, dos pais, de entidades representativas da comunidade em que a escola se insere, e mesmo das empresas que atuam na área em que a escola se insere. Cada escola deve construir sua identidade, elaborar seus programas de trabalho, incluindo a capacitação de professores, tendo em vista projetos e valores educacionais mais amplos, que reflitam o interesse coletivo. A participação dos órgãos governamentais em seus diversos níveis deveria consistir apenas em um agenciamento de instrumentos e competências técnicas para atender às necessidades das escolas. Nessa tarefa, as escolas teriam nas universidades públicas seus parceiros mais solidários.

Na busca de modelos alternativos de gestão das escolas públicas, uma vertente que tem chamado a atenção em tempos recentes é a da colaboração entre escolas e empresas. Uma forma muito freqüente é a da "adoção" de uma escola por determinada empresa. Algumas experiências interessantes têm sido registradas, embora, numericamente, sejam ainda pouco expressivas. Em alguns casos, as atenções têm-se concentrado nos problemas materiais da escola, ou na manutenção da parte física. É fundamental, no entanto, qualquer que seja o nível da colaboração desenhada, que o elemento determinante dessa seja a construção e a realização do projeto educacional da escola. E em tal projeto, o papel determinante não pode ser o do interesse empresarial, devendo ser inteiramente tributário da ativa participação dos pais, da comunidade, da direção, dos professores. Decididamente, a idéia de qualidade nas escolas é muito mais complexa e tem um significado muito peculiar, que pode ser muito distinto da busca da qualidade no mundo empresarial.

\section{Um elemento decisivo: a valorização do professor}

Não existe a possibilidade de uma discussão séria sobre o significado da qualidade da educação sem uma decisão a priori sobre a valorização da função 
docente. Na verdade, mais do que os muitas vezes frágeis indicadores numéricos, resultantes de instrumentos de avaliação nem sempre confiáveis, o maior indício de má qualidade da educação brasileira encontra-se nas precaríssimas condições de trabalho dos professores da Educação Básica. É muito difícil imaginar como um profissional tão desprestigiado, tão desconsiderado em suas funções mais comezinhas possa levar a bom termo as tarefas fundamentais que lhe cabe realizar. Não é possível imaginar-se uma educação de qualidade sob a orientação de profissionais tão desvalorizados quanto o são os professores.

Naturalmente, tal desvalorização não se limita à questão salarial, ainda que essa dimensão ocupe um lugar de destaque. No nível do discurso, todos os planos governamentais pretendem enfrentar essa questão. O falecido Plano Decenal (1993-2003), já anteriormente referido, registra entre suas metas a intenção de "aumentar progressivamente a remuneração do magistério público". O atual Plano de Desenvolvimento da Educação (2007-2022) propõe-se a atingir até o ano de 2010 o piso salarial mensal de R \$ 850,00 (cerca de 430 dólares), como se tal marca representasse um feito considerável.

Reconhecidamente, a questão salarial é bastante complexa e não pode ser considerada desvinculadamente de outros elementos constitutivos da condição de trabalho do professor. O regime de trabalho mais freqüente, por exemplo, baseia-se quase que exclusivamente no número de aulas dadas, em geral excessivamente alto. O trabalho em mais de uma escola, em dois ou mais sistemas de ensino, é outro complicador importante. E é especialmente dissonante a parca participação dos docentes na construção do projeto da escola, na prefiguração de seu rumo, na consolidação de seus valores. Em contrapartida, os professores costumam reagir a tais condições desfavoráveis aceitando pseudocompensações que, se, por um lado, aliviam sua carga de trabalho, por outro, denigrem a imagem do profissional docente. Constituem elementos desse tipo os "direitos" a faltas abonadas, as aposentadorias precoces que vigoraram durante tanto tempo, as distinções de gênero, e os feriados e dias não-letivos em excesso, considerados por muitos um prolongamento artificial das férias regulares. A reivindicação de uma valorização da função docente passa, necessariamente, por uma eliminação progressiva de tais anomalias institucionalizadas.

Uma pretensão equivocada das instâncias governamentais tem sido a de somente melhorar a remuneração e as condições de trabalho após uma capacitação mais adequada dos professores. O equívoco decorre da seguinte armadilha: mantidas as atuais condições de trabalho, quanto mais se capacita o professor da Escola Básica da rede pública, mais ele se afasta dessa, procurando outras ocupações, como o magistério na rede privada, ou o Ensino Superior, público ou privado, em busca de condições materiais mais condizentes. Durante alguns anos, na década de 1990, a prefeitura de uma grande cidade brasileira (Porto Alegre) propiciou aos seus professores do Ensino Fundamental com título de mestre ou doutor uma remuneração equivalente à que teriam se buscassem outros níveis de ensino, compatíveis com sua qualificação. O efeito imediato foi a permanên- 
cia desses professores em suas salas de aulas, elevando consideravelmente o nível do ensino. Já em São Paulo, por exemplo, a existência na USP, há mais de trinta anos, de um Curso de Mestrado em Ensino de Ciências/modalidade Física não significa nenhum diferencial positivo para a rede pública em tal área de atuação. Apesar de já haver formado centenas de mestres, muitos deles com trabalhos especialmente voltados para o Ensino Fundamental, tal programa de capacitação não produz os efeitos desejados na rede, uma vez que a quase totalidade dos professores formados deixou imediatamente de atuar na escola básica, numa busca legítima de melhores condições de trabalho.

A propósito, conviria lembrar que um processo de auto-exclusão gradativa de profissionais do ensino vem ocorrendo há muitos anos. Eles não se resignam com as condições inadequadas de trabalho e migram do magistério para outras atividades em que suas competências soem ser mais valorizadas. A reversão de tal processo deve, necessariamente, começar pela melhoria das condições de trabalho, associada, como já se registrou, a um aumento no nível correspondente de exigências para o exercício da função docente. Os efeitos de tal melhoria devem levar algum tempo para aparecer e não parece haver outra saída senão o Estado investir com paciência nesse sentido.

Também parece equivocada a busca de uma correlação imediata entre os eventos melhoria da qualidade de ensino e melhoria dos niveis salariais em experiências tópicas. De fato, se um professor é remunerado proporcionalmente ao número de horas de aula que leciona, e é levado a ministrar trinta ou quarenta aulas por semana, por mais que seu salário-aula seja elevado, sua condição de trabalho não é boa. Uma efetiva melhoria nas condições de trabalho deve incluir os níveis de remuneração, mas não pode esgotar-se neles.

Uma providência interessante, ao que tudo indica ainda não suficientemente testada, seria a consideração da carreira docente de modo integrado, nos diversos níveis de ensino da rede pública. A desejável aproximação entre a universidade e a Educação Básica, por exemplo, cujos efeitos parecem bastante nítidos quando se pensam os meios de capacitação docente, poderia ter um impulso bastante eficaz se tivesse uma âncora, um padrão de referência nas questões salariais. Se, por exemplo, um professor da rede pública nos níveis iniciais do ensino concluísse um mestrado em uma universidade pública, deveria ser-lhe facultada, imediatamente, a permanência em sua sala de aula da escola básica, fazendo jus à remuneração do professor universitário com o título de mestre; situação análoga deveria ocorrer com aquele que conquistasse um doutorado. Ainda que o número de ocorrências de tais docentes especialmente capacitados, pelo menos inicialmente, não fosse grande, cada um desses docentes, enraizado em seu local de trabalho, passaria a constituir uma referência, um pólo irradiador, um estímulo para a formação adicional dos demais. E o custo adicional para o poder público, inicialmente muito pequeno, seria administrável, pelo seu caráter progressivo.

Durante muitos anos, a rede de escolas técnicas federais representou um ensino público de excelência, no nível do Ensino Médio. As reformas por que 
passaram no final dos anos 1990 modificaram substancialmente suas condições de funcionamento. Deixando de propiciar o Ensino Médio completo, elas se tornaram incomparáveis com o ensino regular desse nível. Um elemento fundamental para o prestígio de que justamente desfrutavam era a existência de uma carreira e de um regime de trabalho para seus professores diretamente relacionados com os correspondentes dos professores das universidades federais. Em alguns dos Colégios de Aplicação de universidades federais, a articulação entre os diversos níveis da carreira docente existe efetivamente e produz efeitos interessantes na organização do ensino.

De modo geral, consideramos que a carreira docente exige um profissionalismo em seu grau mais elevado. Ela pressupõe, muito além da competência técnica, uma dedicação extrema e um compromisso público com os projetos e os valores socialmente acordados. De modo análogo ao dos profissionais da saúde e da justiça, os professores não poderiam estar submetidos apenas à lógica e às exigências do mercado, não deveriam ser remunerados como se produzissem automóveis ou alfinetes. A educação, a saúde e a justiça são condições de possibilidade de construção de uma cidadania plena; o respeito e a valorização dos profissionais de tais áreas situam-se na ante-sala da constituição de uma real democracia em sentido moderno.

\section{Uma lembrança: o diagnóstico de Anísio Teixeira}

Nenhum dos cinco lembretes aqui relacionados apresenta qualquer elemento novo ou original: a crise da educação brasileira é proclamada há muitas décadas. Em um texto seminal escrito em 1953, intitulado precisamente $A$ crise educacional brasileira, Anísio Teixeira produziu um diagnóstico profundo da situação de então, seguido de uma espécie de decálogo, que prefigura as ações a serem implementadas. A perenidade das questões tratadas e a profundidade das análises realizadas tornam a leitura do referido texto (Teixeira, 1999) especialmente instigante e fecunda. Além de uma compreensão densa e clara do processo de formação da sociedade brasileira, Anísio Teixeira aliava à sua visão teórica uma permanente busca do enraizamento institucional de suas idéias, sendo, justamente, chamado de criador de instituições. Não surpreendem, portanto, a pertinência e a atualidade das propostas apresentadas pelo eminente educador, que reproduzimos, a seguir, ainda que de modo sintético.

Já na abertura, o texto anuncia que "Não é difícil encontrar-se um relativo consenso de opinião a respeito da gravidade da situação educacional brasileira. A divergência surge na análise das causas dessa situação e na indicação da terapêutica mais aconselhável" (ibidem, p.43).

Após uma análise extensa e acurada da ambigüidade com que o Estado trata a educação pública, desde os primórdios da formação da nação brasileira, enfatizando a permanente dualidade de objetivos - formação geral versus formação para o trabalho - e as relações nem sempre bem equacionadas entre o ensino público e o privado, Teixeira caracteriza em grandes linhas a crise educacional 
brasileira, propondo uma súmula de providências para superá-la. Dez são as medidas vislumbradas pelo eminente educador:

Primeiro, descentralizar administrativamente o ensino, para que a tarefa se torne possível, com a distribuição das responsabilidades pela execução das medidas mais recomendáveis e recomendadas.

Trata-se, sem dúvida, do passo inicial, condição sine qua non para a viabilização de todos os outros. A unidade do sistema educacional somente faz sentido no terreno dos projetos e dos valores socialmente acordados que os orientam; as ações a serem implementadas somente podem efetivamente realizar-se em sintonia com os interesses e as peculiaridades locais, sendo vã qualquer tentativa de administrar a dinâmica dos processos educativos a partir de um gabinete na capital federal.

Segundo, mobilizar recursos financeiros para a Educação, de forma a obter deles maiores resultados. Sugerimos a constituição, com percentagens previstas na lei magna da República, de fundos de educação - federal, estaduais e municipais; estes fundos, administrados por conselhos, organizados com autonomia financeira, administrativa e técnica e todos os poderes necessários para a aplicação dos recursos, inclusive no pagamento de empréstimos e planos de inversões e dos quadros do pessoal e do magistério locais (com tabelas de vencimentos locais), permitindo, assim, a adaptação da escola às condições econômicas de cada localidade.

É fundamental atinar-se para a ordem das providências: primeiro, descentralizar; depois, providenciar os fundos. De fato, a idéia da criação de fundos, em vigor, já há algum tempo, entre nós, com o Fundo de Manutenção e Desenvolvimento do Ensino Fundamental e de Valorização do Magistério (Fundef), e agora, com o Fundo de Manutenção e Desenvolvimento da Educação Básica e de Valorização dos Profissionais da Educação (Fundeb), bem como a fixação de porcentagens orçamentárias sem a correspondente descentralização das decisões, sem a consolidação prévia da prática da autonomia no que se refere aos projetos educacionais e aos valores locais, somente pode conduzir, como habitualmente tem ocorrido, a desvios de função ou a distorções caricatas na caracterização dos gastos educacionais.

Terceiro, estabelecer a continuidade do sistema educacional, com a escola primária obrigatória, o ensino médio variado e flexível e o ensino especializado e superior rico e seletivo.

Eis aí outro ponto notável na súmula de providências: a necessária continuidade entre os diversos níveis do ensino. Para pensar com seriedade a educação, impõe-se o equacionamento de tal continuidade, com o equilíbrio nas articulações, no exercício das funções básicas e na destinação de recursos a cada setor. Em nenhuma hipótese, pode justificar-se uma contraposição da importância relativa, ou uma fratricida disputa de verbas, tão absurda quanto seria a hipótese de que o sistema educacional pudesse prescindir de qualquer uma de 
suas instâncias, cada uma delas com suas peculiaridades, e sem tergiversações sobre a natural seletividade do Ensino Superior.

Quarto, prolongar o período escolar ao mínimo de seis horas diárias, tanto no primário quanto no médio, acabando com os turnos e só permitindo o ensino noturno como escolas de continuação, para suplementação da educação.

Um ponto crucial no elenco das ações propostas é o tempo de permanência dos alunos na escola. Segundo Teixeira, a redução desse tempo praticamente inviabiliza o exercício da influência, necessária e inspiradora, dos professores sobre os alunos. O contato superficial entre parceiros assoberbados e apressados no máximo pode possibilitar a inculcação de conteúdos supostamente teóricos ou de noções simploriamente consideradas práticas. Não viabiliza a formação de hábitos, não contribui para edificar atitudes, para moldar o caráter, para estimular ideais ou aspirações de crescimento pessoal.

Quinto, alterar as condições de trabalho do professor, proporcionando-lhe novas bases de remuneração, para não the reduzir o período de influência aos escassos minutos de aula. Toda educação é influência de uma pessoa sobre outra, demanda tempo, e nas condições atuais não há tempo para se exercer tão imprescindível influência.

Como se pode ver, a preocupação com as condições de trabalho dos professores tem raízes fundas, ainda que poucas vezes tenha sido formulada de maneira tão simples e nítida. Não se trata apenas, como já se registrou anteriormente, de reivindicar melhores salários, mas, sobretudo, de se garantir a possibilidade do estabelecimento de espaços de convivência, de orientação, de tutoria, em que se desenvolvem relações interpessoais inspiradoras, depuradoras, assimétricas, como soem ser as relações entre professores e alunos.

Sexto, eliminar todos os modelos e imposições oficiais que estão a produzir efeitos opostos aos previstos, servindo até como justificativa para o mau ensino - como é o caso dos programas oficiais, dos livros didáticos aprovados e do currículo rígido e uniforme.

Em nenhum dos dez pontos da súmula proposta, a realidade atual situase mais distante do ideal anisiano do que nessa sexta medida. De fato, todas as ações governamentais, nos diversos níveis de ensino, parecem apontar no sentido oposto ao prefigurado antes: os livros didáticos exibem etiquetas ou logotipos que garantem um pleno acordo com os Parâmetros Curriculares Nacionais (PCN), os modelos de capacitação docente buscam atender a uma demanda genérica, como se todos os professores precisassem dos mesmos cursos, os processos de avaliação ignoram os projetos locais, disseminando uma busca de padronização que pode ser suicida para as instituições mais bem-sucedidas.

Sétimo, permitir que os dois primeiros anos do curso secundário se façam, complementarmente, nos bons grupos escolares, com auxílio dos melhores professores primários e redução do número de professores nesses cursos a quatro, ou, no máximo, cinco. 
Esse sétimo ponto parece uma reiteração tópica da preocupação explicitada na terceira ação proposta, referente à continuidade entre os diversos níveis do sistema educacional. De fato, a diferença de formação e de perspectivas entre os professores da antiga escola primária e os dos antigos cursos ginasiais, que tanto preocupava o educador, permanece praticamente inalterada ainda hoje, com as novas roupagens terminológicas do Ensino Fundamental I e do Ensino Fundamental II. E o recém-criado Ensino Fundamental de nove anos certamente irá amplificar os problemas vislumbrados por Teixeira, na medida em que abrangerá professores com três níveis de formação, incluindo-se, agora, os da Educação Infantil.

Oitavo, estabelecer o exame de Estado para a admissão; ao primeiro ano ginasial; ao terceiro ginasial; ao primeiro colegial e ao colégio universitário, mantido o vestibular para a entrada na universidade.

Novamente, nesse ponto, ainda que a nomenclatura oficial tenha se modificado substancialmente, a preocupação expressa do educador é a da viabilização de uma efetiva continuidade entre os diversos níveis de ensino, construindo-se instrumentos de Estado para garantir uma progressão baseada no mérito, que não corrompa o ideal de ampla aprovação, transformando-o em mera fabricação de indicadores artificialmente favoráveis.

Nono, dividir o curso superior regular em dois ciclos - o básico e o profissional, autorizando nas escolas novas ou sem recursos adequados apenas o curso básico, e exigindo o exame de Estado para a entrada no curso profissional e nos de pós-graduação.

É na passagem do Ensino Médio para o Ensino Superior que se encontra, provavelmente, o máximo de descontinuidade entre os diversos níveis de ensino. Embora seja, freqüentemente, responsabilizado por tal desnível, o vestibular, na verdade, apenas responde de modo adequado à forma como a universidade se organiza: é na universidade que se devem procurar as raízes ou as razões da enorme fragmentação disciplinar, que o vestibular não cria, mas apenas reflete. Atento a tal questão, Teixeira propõe uma reorganização do Ensino Superior, com a criação de um ciclo básico, de formação geral, com o centro de gravidade na cultura, sem vinculações precoces com a formação profissional. Ainda que de forma nem sempre consentânea aos ideais anisianos, a idéia de um curso universitário básico periodicamente retorna ao centro das discussões, em múltiplos avatares.

Décimo, facultar no ensino superior a constituição de cursos variados de formação, em diferentes níveis, de técnicos e profissionais médios, prevendo sempre a possibilidade de poderem os assim diplomados continuar, ulteriormente, os estudos e terminar os cursos regulares.

Eis mais um ponto em que se destaca o descortino do educador. A perspectiva de uma flexibilização da formação inicial, em todas as áreas, juntamente com a consolidação da consciência sobre a necessidade de uma formação conti- 
nuada, que aliás tende a esmaecer o significado do término dos cursos regulares, já se encontrava no horizonte das ações educacionais propostas.

Como se pode depreender da observação da súmula anisiana, a busca da superação da crise educacional brasileira, com a criação das condições para o florescimento de uma educação pública de qualidade, situa-se muito além do terreno dos recursos financeiros, das escolhas metodológicas, ou dos materiais didáticos disponíveis. No cerne das questões educacionais, encontram-se os projetos que prefiguram o país que queremos construir. Nas palavras do próprio Anísio Teixeira,

A Pátria é menos o seu passado que os seus projetos de futuro. Está claro que esses projetos de futuro mergulham as suas raízes no passado e se apóiam no presente. Mas, a sua força vem antes dos objetivos antevistos, da sua projeção no amanhã, do que dos nossos pontos de apoio em nossa história, ainda não de todo livre de incertezas e fragilidades. [...] Do ponto de vista social, mais amplo ou mais elevado, temos que dar à escola a função de formar hábitos e atitudes indispensáveis ao cidadão de uma democracia... Não será a instituição decorativa pretensamente destinada à ilustração dos seus alunos, mas a casa que ensine a ganhar a vida e a participar inteligente e adequadamente da sociedade... E é sobre a base desse sistema fundamental, comum e popular de educação, que teremos de formar verdadeiras, autênticas elites, dando aos mais capazes as oportunidades máximas de desenvolvimento.

A análise de ações educacionais, como o recentemente lançado Plano de Desenvolvimento da Educação (abril de 2007), não nos enche de esperança, na medida em que as atenções se concentram em aspectos perfunctórios da crise em questão. Em artigo publicado em jornal de grande circulação (OESP, 29.4.2007), o professor José de Souza Martins assim traduz as ações, as intenções e as limitações do referido plano:

O Plano de Desenvolvimento da Educação... tem tudo o que é necessário para melhorar a qualidade física e o funcionamento de muitas escolas no País. Mas tem muito pouco de plano de desenvolvimento da educação propriamente dito, a não ser nos efeitos colaterais de longo prazo... Já tivemos um bom sistema educacional, ainda que com o defeito da seletividade injusta. Muitos dos grandes nomes da universidade de hoje, vindos do povo, passaram por ele. Esse sistema entrou em colapso com a aplicação de regras contábeis à educação... o professor do ensino elementar e médio foi transformado num caixeiro-viajante da educação, dando aulas por hora... a educação foi transformada num remendo e numa condenação, sobretudo dos pobres, às vicissitudes do ensino meia-boca. A escola se transformou em equivalente da quitanda... Professores dedicados e competentes foram transformados em sucata. Anularam-se no refúgio do corporativismo sindical auto-defensivo e estéril... Pensar a educação a sério só tem sentido em nome da esperança, que seja esperança do gênero humano, esperança de todos e não só dos que compreendem a educação na incivilizada, autoritária e pobre concepção da política com oportunidade da vendeta das minorias. E não como ação democrática em favor de todos para vencer nossas insuficiências sociais e alargar nossas possibilidades históricas. 
A crise quase permanente que mina a qualidade de nossa educação tem raízes nos fins que a orientam muito mais do que nos meios para viabilizá-los. É preciso reavivar o sentido de nossa luta no espaço escolar, os valores que nos orientam, os projetos que nos mobilizam coletivamente. Na formulação de planos educacionais, questões extremamente relevantes têm sido efetivamente consideradas, mas, em sua análise, os meios têm prevalecido sobre os fins. Em conseqüência, os contabilistas ou os economistas parecem ter mais a nos dizer do que os educadores, os sonhadores, os filósofos ou os poetas. Reflexões como as de Anísio Teixeira nos ajudam a manter viva a esperança no futuro, por meio da lembrança de que não é possível separar a educação da cultura, a razão prática dos sentimentos, nem a economia da poesia, ao tratar da crise e da qualidade da educação.

Referências bibliográficas

MACHADO, N. J. Cidadania e educação. São Paulo: Escrituras, 1997.

TEIXEIRA, A. Educação no Brasil. Rio de Janeiro: Editora UFRJ, 1999.

RESUMO - O texto examina o aparente consenso sobre a má qualidade da Educação Básica no Brasil. Destaca cinco aspectos da questão, cinco lembretes sem cuja consideração não parece possível vislumbrar alternativas de ações concretas, tendo em vista o enfrentamento dos problemas: a existência de ilhas educacionais de boa qualidade, que têm sido ignoradas pelas políticas públicas; a ineficácia dos múltiplos instrumentos de avaliação, cujos resultados limitam-se a inspirar manchetes espetaculares; a falta de articulação entre os diversos níveis de ensino; a parca autonomia da unidade escolar, que deveria constituir a unidade fundamental na relação entre o poder público e a rede de ensino; a falta de ações explícitas no sentido da melhoria das condições de trabalho dos professores. Um artigo seminal escrito por Anísio Teixeira, em 1953, constitui uma fecunda lembrança que parece corroborar grande parte dos lembretes anunciados.

PALAVRAS-CHAVE: Educação, Qualidade, Avaliação, Escola, Professores.

ABSTRACT - This paper examines the apparent consensus on the bad quality of Brazilian Elementary and Secondary Education. It emphasizes five indispensable aspects of the subject that one should keep in mind in order to plan concrete actions to face the problems. They are: the existence of "educational islands" of good quality, usually neglected by public policies; the inefficacy of the multiple assessment tools, whose results are mainly used as an inspiration for fantastic newspapers' headlines; the inexistence of a more effective articulation among the different levels of education; the lack of autonomy of the schools as fundamental unities in the structure of the public education organization; and the need of explicit actions to improve the work conditions of teachers. An old and seminal article (Anísio Teixeira, 1953) is evoked by the author, in order to corroborate some of the aspects presented in the paper.

KEYWORDS: Education, Quality, Assessment, School, Teachers.

Nílson José Machado é professor da Faculdade de Educação da Universidade de São Paulo. @-njmachad@usp.br

Recebido em 10.8.2007 e aceito em 20.8.2007. 